\title{
trans-Stilbenoids with Extended Fluorescence Lifetimes for the Characterization of Amyloid Fibrils
}

\author{
Jun Zhang, ${ }^{\dagger}$ Alexander Sandberg, ${ }^{\dagger}$ Xiongyu Wu, ${ }^{\dagger}$ Sofie Nyström, ${ }^{\dagger}$ Mikael Lindgren, ${ }^{\ddagger}$ Peter Konradsson, ${ }^{\dagger}$ \\ and Per Hammarström ${ }^{*}, \dagger$
}

${ }^{\dagger}$ IFM-Department of Chemistry, Linköping University, Linköping 581 83, Sweden

${ }^{\ddagger}$ Department of Physics, The Norwegian University of Science and Technology, 7491 Trondheim, Norway

\section{Supporting Information}

ABSTRACT: It was previously reported that two naphthyl-based transstilbene probes, (E)-4-(2-(naphthalen-1-yl)vinyl)benzene-1,2-diol (1) and (E)-4-(2-(naphthalen-2-yl)vinyl)benzene-1,2-diol (3), can bind to both native transthyretin (TTR) and misfolded protofibrillar TTR at physiological concentrations, displaying distinct emission maxima bound to the different conformational states ( $>100 \mathrm{~nm}$ difference). To further explore this amyloid probe scaffold to obtain extended fluorescence lifetimes, two new analogues with expanded aromatic ring systems (anthracene and pyrene), (E)-4-(2-(anthracen-2-yl)vinyl)benzene-1,2-diol (4) and (E)-4-(2-(pyren-2-yl)vinyl)benzene-1,2-diol (5), were synthesized employing the palladium-catalyzed MizorokiHeck reaction. (E)-4-Styrylbenzene-1,2-diol (2), 3, 4, and 5 were investigated with respect to their photophysical properties in methanol and when bound to insulin, lysozyme, and $\mathrm{A} \beta 1-42$ fibrils, including time-resolved fluorescence measurements. In conclusion, 4 and 5 can bind to both native and fibrillar TTR, becoming highly fluorescent. Compounds 2-5 bind specifically to insulin, lysozyme, and A $\beta 1-42$ fibrils with an apparent fluorescence intensity increase and moderate binding affinities. The average fluorescence lifetimes of the probes bound to A $\beta 1-42$ fibrils are $1.3 \mathrm{~ns}(2)$, $1.5 \mathrm{~ns}$ (3), $5.7 \mathrm{~ns}$ (4), and $29.8 \mathrm{~ns}$ (5). In summary, the variable aromatic moieties of the para-positioned trans-stilbenoid vinylbenzene-1,2-diol with benzene, naphthalene, anthracene, and pyrene showed that the extended conjugated systems retained the amyloid targeting properties of the probes. Furthermore, both the anthracene and pyrene moieties extensively enhanced the fluorescence intensity and prolonged lifetimes. These attractive probe properties should improve amyloid detection and characterization by fluorescence-based techniques.

\section{INTRODUCTION}

Many aspects of amyloid fibrils have been studied owing to their association with a variety of human diseases, such as Alzheimer's disease, type II diabetes, amyloidosis, and others. ${ }^{1-7}$ Amyloid fibrils form when native proteins misfold and self-assemble into insoluble aggregates, ${ }^{8,9}$ which are deposited in organs or tissues where the aggregates have a pathogenic effect. ${ }^{10} \mathrm{Up}$ to date, several characteristics of the amyloid fibril structure are widely accepted, for example, (1) mature fibrils are composed of parallel $\beta$-strands, which are oriented perpendicular to the long fibril axis, ${ }^{3,7,11,12}$ (2) mature fibrils have variable lengths up to several micrometers with a width between 8 and $10 \mathrm{~nm}$ and are often twisted and are generally unbranched. ${ }^{11-13}$ It has been recently reported that most proteins could form amyloid fibrils under specific conditions $^{14,15}$ and that fibril formation is an intrinsic property of the polypeptide backbone. ${ }^{3}$

Characterization of amyloid fibrils has been performed by using various spectroscopic and microscopic techniques, such as atomic force and electron microscopy, circular dichroism, Fourier transform infrared, luminescence, and others. ${ }^{16-18}$ The most commonly used, fast, and reliable method for spectroscopic determination of amyloid fibril formation is by using fluorescent dyes, such as luminescent conjugated poly-, and oligothiophenes ${ }^{19,20}$ (LCP/LCO), Congo red (CR), or thioflavin $\mathrm{T}$ (ThT). Furthermore, upon binding to amyloid fibrils, CR generates a characteristic apple-green birefringence when viewed through crossed polarizers, and a characteristic red shift in absorbance maximum from about $490 \mathrm{~nm}$ to about $540 \mathrm{~nm} \cdot{ }^{21-24}$ However, it has been reported that CR can bind to native proteins. ${ }^{24} \mathrm{ThT}$, a charged molecular rotor molecule, shows an apparent fluorescence intensity increase upon binding to fibrils and its binding property is different at acidic and neutral $\mathrm{pH}^{25-28}$ and it has been reported to bind poorly to transthyretin (TTR) fibrils at an acidic $\mathrm{pH} .{ }^{29}$ In addition, both LCOs and ThT have a relatively short fluorescence lifetime with average $t_{1 / 2}<1 \mathrm{~ns} .{ }^{29}$ We have previously demonstrated the power of time-resolved fluorescence for the characterization of

Received: April 30, 2017

Accepted: July 13, 2017

Published: August 18, 2017 
Chart 1. Chemical Structures of trans-Stilbenoids ${ }^{a}$<smiles>CNc1ccc(/C=C/c2ccnc(OCCOCCOCCC(F)(F)F)c2)cc1</smiles><smiles>Oc1ccc(/C=C/c2cccc3ccccc23)cc1O</smiles><smiles>Oc1ccc(/C=C/c2ccc(O)c(/C=C/c3ccc4ccccc4c3)c2)cc1O</smiles><smiles></smiles>

${ }^{a} \mathbf{1}, \mathbf{2}$, and $\mathbf{3}$ have been reported previously by our group. ${ }^{36} \mathbf{4}$ and $\mathbf{5}$ were synthesized in this paper.

oligomerization of amyloid proteins, allowing both real-time detection of oligomerization and size distribution analysis. ${ }^{17,29}$ Especially, a noncovalent small-molecule amyloid targeting probe with an extended lifetime is desirable in this regard. Here, there is ample room for current probe improvement to facilitate detection and characterization of amyloid protein structures. Such probes that utilize both spectral and temporal differences open up alternative modes of detection, for example, fluorescence lifetime imaging and related methods. ${ }^{30,31}$

In recent years, various trans-stilbene-based probes for the detection of amyloid fibrils and amyloidogenic proteins have been reported (Chart 1). The Kelly group has reported that resveratrol can bind native TTR and becomes fluorescent. ${ }^{32,33}$ $\left[{ }^{11} \mathrm{C}\right] \mathrm{BF}-227$ and ${ }^{18} \mathrm{~F}$-florbetapir containing a trans-stilbenoid structure have been successfully used as positron emission tomography ligands to trace cardiac TTR amyloid. ${ }^{34,35}$ Previously, we successfully developed two naphthyl-based trans-stilbene probes, (E)-4-(2-(naphthalen-1-yl)vinyl)benzene-1,2-diol (1) and (E)-4-(2-(naphthalen-2-yl)vinyl)benzene-1,2-diol (3), that can bind both native TTR and misfolded protofibrillar TTR at physiological concentrations. ${ }^{36}$ These probes displayed distinct shift in emission maxima $(>100$ $\mathrm{nm}$ ) when bound to the two different TTR conformations, allowing conformational discrimination by fluorescence spectroscopy. Hence, this class of compounds having a transstilbene or trans-stilbenoid structure are indeed a promising fluorescent probe scaffold for amyloid research. Accordingly, we designed and prepared two new analogues ( 4 and 5 , see the structures in Chart 1), where the naphthyl was replaced by anthracenyl or pyrenyl to investigate their spectral discrimination of binding native and protofibrillar TTR as well as three other canonical amyloid proteins. Subsequently, the emission properties of these analogues (2-5) with different aromatic ring moieties were investigated using steady-state and timeresolved fluorescence spectroscopies, which demonstrate the feasibility of these new scaffolds for amyloid fibril characterization.

\section{EXPERIMENTAL SECTION}

Materials and Methods. All chemicals were obtained from conventional commercial sources and used without further purification unless otherwise noted. The synthesis of compound 2-(Bpin)pyrene (6) was performed according to the literature. ${ }^{37-39}$ The synthesis of compound 2-bromopyrene
(7) was carried out according to the literature. ${ }^{39-41} 3,4-$ Dimethoxystyrene (9) was synthesized according to the literature. $^{42,43}$ The synthetic method of compounds $\mathbf{4}$ and 5 is shown in the Supporting Information. Thin layer chromatography was performed on Merck silica gel $60 \mathrm{~F}_{254}$ glass-backed plates. Flash chromatography was carried out with silica gel 60. Nuclear magnetic resonance (NMR) spectra were recorded on a Varian AVANCE $300 \mathrm{MHz}$ instrument with solvent indicated. The ${ }^{1} \mathrm{H}$ NMR and ${ }^{13} \mathrm{C}$ NMR chemical shifts are reported in parts per million relative to tetramethylsilane or the residual solvent protons.

Amyloid Fibril Formation. WT TTR was isolated and purified, as previously described. ${ }^{44}$ The TTR protein concentration was determined using the molar extinction coefficient $(\varepsilon)$ of the monomeric TTR $18289 \mathrm{M}^{-1} \mathrm{~cm}^{-1}$ at 280 $\mathrm{nm}{ }^{45}$ The fibrillation of native TTR in $\mathrm{dH}_{2} \mathrm{O}$ was induced by adding a stock solution of $1 \mathrm{M} \mathrm{NaAc}$ and $2 \mathrm{M} \mathrm{NaCl}$ to a final concentration of $50 \mathrm{mM} \mathrm{NaAc}$ and $100 \mathrm{mM} \mathrm{NaCl}$ (final $\mathrm{pH}$ 3.0). Concentration of the insulin was determined by using $\varepsilon=$ $5840 \mathrm{M}^{-1} \mathrm{~cm}^{-1}$ at $277 \mathrm{~nm}$. Bovine insulin fibril formation was initiated by incubating $200 \mu \mathrm{M}$ in $25 \mathrm{mM} \mathrm{HCl}(\mathrm{pH} 1.6)$ at 65 ${ }^{\circ} \mathrm{C} .{ }^{46}$ The chicken egg-white lysozyme protein concentration was determined using the $\varepsilon=37752 \mathrm{M}^{-1} \mathrm{~cm}^{-1}$ at $280 \mathrm{~nm}$, and fibril formation was initiated using $200 \mu \mathrm{M}$ at $65^{\circ} \mathrm{C}$ in $25 \mathrm{mM}$ $\mathrm{HCl}(\mathrm{pH} 1.6) .^{46,47}$ Insulin and lysozyme fibrils were dialyzed against $50 \mathrm{mM} \mathrm{NaAc}$ and $100 \mathrm{mM} \mathrm{NaCl}$ (final $\mathrm{pH}$ 3.0) prior to measurements. Recombinant $\mathrm{A} \beta 1-42$ was expressed and purified using the system described by Linse and co-workers, ${ }^{48}$ containing an additional methionine in the $\mathrm{N}$-terminus. Before the final step, the lyophilized A $\beta 1-42$ sample was solubilized in $6 \mathrm{M} \mathrm{GuHCl}$ before gel filtration on a Superdex 75 10/300 column (GE-Healthcare) in phosphate-buffered saline (PBS) buffer $\mathrm{pH}$ 7.5. Freshly monomeric gel filtered $\mathrm{A} \beta 1-42$ was used in all experiments. Peptide $A \beta 1-42$ (Atlanta, GA, USA) without $\mathrm{N}$-terminal methionine from HFIP was also dissolved in $6 \mathrm{M}$ $\mathrm{GuHCl}$ and gel filtered to make comparable preparations. $\mathrm{A} \beta 1$ 42 protein concentration was calculated using $\varepsilon=1490 \mathrm{M}^{-1}$ $\mathrm{cm}^{-1}$ at $277 \mathrm{~nm}$. The $\mathrm{A} \beta 1-42$ fibrils were generated through incubation of $10 \mu \mathrm{M} \mathrm{A} \beta 1-42$ at $37{ }^{\circ} \mathrm{C}$ in PBS buffer ( $\mathrm{pH} 7.5$ ) for $24 \mathrm{~h}$ under quiescent conditions. Fibril formation of TTR, insulin, lysozyme, and $\mathrm{A} \beta 1-42$ was verified using the ThT (neutral $\mathrm{pH}$ ) and $\mathrm{X}-34$ (acidic $\mathrm{pH}$ ) fluorescence assays.

UV-Vis Absorption Measurements. The ultravioletvisible (UV-vis) absorption measurements were carried out 
Scheme 1. Synthesis of Compounds 4 and $5^{a}$

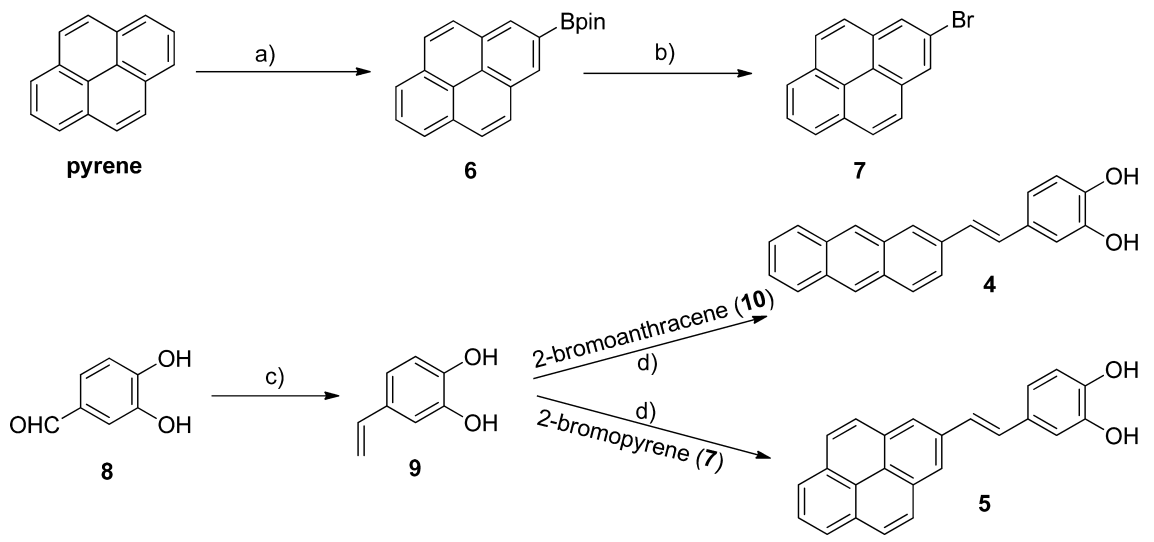

${ }^{a}$ Reagents and conditions: (a) $\mathrm{B}_{2} \operatorname{Pin}_{2}$ (1.1 equiv), $[\operatorname{Ir}(\mathrm{u}-\mathrm{OMe}) \operatorname{cod}]_{2}(1 \mathrm{~mol} \%)$, dtbpy $(2 \mathrm{~mol} \%)$, hexane, $80{ }^{\circ} \mathrm{C}$, overnight, $60 \%$. (b) $\mathrm{CuBr}{ }_{2}(3$ equiv), methanol $/ \mathrm{H}_{2} \mathrm{O}(1: 1), 90{ }^{\circ} \mathrm{C}$, overnight, $75 \%$. (c) $\mathrm{Ph}_{3} \mathrm{PCH}_{3} \mathrm{Br}$ (1.5 equiv), $t$-BuOK (4 equiv), THF, rt, $6 \mathrm{~h}, 58 \%$. (d) $\mathrm{Pd}(\mathrm{OAc}){ }_{2}(20 \% \mathrm{~mol}$ ), triethanolamine (4 equiv), dry DMF, $100{ }^{\circ} \mathrm{C}, 24 \mathrm{~h}$. [ $\operatorname{Ir}(\mu$-OMe $\left.) \operatorname{cod}\right]_{2}=(1,5$-cyclooctadiene $)($ methoxy $)$ iridium $(\mathrm{I})$ dimer, dtbpy $=4,4^{\prime}$-di-tert-butyl$2,2^{\prime}$-dipyridyl.

employing a Cary winUV 100 spectrophotometer, using a $1 \mathrm{~cm}$ quartz cuvette at room temperature. The concentration of each probe was $20 \mu \mathrm{M}$ in methanol.

Fluorescence Spectroscopy Measurements. All fluorescence spectra for each probe in methanol $(20 \mu \mathrm{M})$ were recorded in a Tecan Safire 2 Microplate reader (Tecan, Männerdorf, Switzerland) or a Tecan infinite M1000 instrument and collected between 350 and $600 \mathrm{~nm}$ with the excitation wavelength at $330 \mathrm{~nm}$ at $1 \mathrm{~nm}$ spectral resolution. Fluorescence analysis for each probe upon binding to native protein or amyloid fibrils was carried out by mixing $1.0 \mu \mathrm{M}$ of each molecule from a dimethyl sulfoxide (DMSO) stock with 5 $\mu \mathrm{M}$ proteins or fibrils (on a monomer basis) in PBS buffer ( $\mathrm{pH}$ 7.5) or HOAc/ $\mathrm{NaAc}$ buffer $(\mathrm{pH} 3.0)$ for native proteins or fibrils, except for both native (freshly dissolved monomeric) $\mathrm{A} \beta 1-42$ and $\mathrm{A} \beta 1-42$ fibrils in PBS buffer.

To avoid solubility problems for the probes, we used variable fibril concentrations to a fixed low concentration of probe to determine the binding affinity. A mixture $(100 \mu \mathrm{L})$ containing each probe (final concn 1 or $0.5 \mu \mathrm{M}$ for $\mathrm{A} \beta 1-42$ fibrils) and fibrils (final concn $0-20 \mu \mathrm{M}$ on a monomer basis) was incubated at room temperature for $30 \mathrm{~min}$ to achieve equilibrium. To assess the binding interactions in supermolecular chemistry is not trivial. ${ }^{49}$ Especially, this is true for amyloid fibrils that are known to be structurally heterogenous and may contain several binding pockets for each fibril type. ${ }^{50}$ For this assay, we assumed that the fluorescence increase in the complex between the fibril and the compound reports on binding. A high-resolution probe binding pocket within model amyloid fibrils has been defined, ${ }^{51}$ where CR (an analogous molecule to our compounds) needs a defined pocket of sufficient order lined by side chains to bind. From this model, it is observed that a molecule of CR binds across six $\beta$-strands. In comparison, the compounds of this study are half the size of $\mathrm{CR}$ and hence should span three $\beta$-strands. From the experimental data, we assumed the simplistic model of one saturable binding site for each fibril protein. The fluorescence spectra were collected between 350 and $700 \mathrm{~nm}$ with excitation at $330 \mathrm{~nm}$. The dissociation constant $\left(K_{\mathrm{d}}\right)$ of amyloid fibrils to each probe was calculated by GraphPad Prism 7.01 using nonlinear fit with one binding site and a fixed $B_{\max }$ adjusting for the signal from the unbound compound. All binding curves and fits are shown in the Supporting Information.

Fluorescence Lifetime Measurements. Fluorescence decays were performed using an IBH time-correlated single photon counting (TCSPC) spectrometer. The solution of each probe in methanol was degassed with an argon gas, whereas the solution of each probe incubated with amyloid fibrils was not. After the sample solution was excited at $337 \mathrm{~nm}$, the fluorescence decays at each respective emission maximum for each probe either free in methanol or bound to fibrils were monitored at room temperature. The instrument response function was determined with a fibril solution. Decays were fitted with a sum of exponentials (eq 1), and the quality of the fit was determined from the $\chi^{2}$ parameter, the random distribution of the residuals, and the autocorrelation of the residuals.

$$
I(t)=\sum_{i} \alpha_{i} \exp \left(-t / \tau_{i}\right)
$$

where $\alpha_{i}$ is the pre-exponential factor associated with the decay time $\tau_{i}$. The average lifetime of fluorescence decay was calculated according to the following equation

$$
\tau_{\text {avg }}=\frac{\sum \alpha_{i} \tau_{i}^{2}}{\sum \alpha_{i} \tau_{i}}
$$

\section{RESULTS AND DISCUSSION}

Synthesis and Optical Characterization of transStilbenoid Derivatives. Our approach for the synthesis of the trans-stilbene derivatives $\mathbf{4}$ and $\mathbf{5}$ was to apply the palladium-catalyzed Mizoroki-Heck reaction of $\mathbf{9}$ to the corresponding 2-bromopyrene (7) and 2-bromoanthracene (10). Marder et al. have reported the synthesis of 2- and 2,7functionalized pyrene derivatives including compounds 6 and 7 (Scheme 1). ${ }^{37-41}$ Employing the catalyst that was prepared in situ by the reaction of $[\operatorname{Ir}(\mathrm{u}-\mathrm{OMe}) \operatorname{cod}]_{2}$ with $4,4^{\prime}$-di-tert-butyl$2,2^{\prime}$-dipyridyl (dtbpy), the product 6 was obtained in $62 \%$ yield. Then, the reaction of compound 6 with 3 equiv of $\mathrm{CuBr}_{2}$ in methanol $/ \mathrm{H}_{2} \mathrm{O}(1: 1)$ gave 7 in $78 \%$ yield. From 3,4dihydroxybenzaldehyde (8), 9 was obtained by a witting reaction in 59\% isolated yield, in which the Mizoroki-Heck 
reaction with 10 and 7 yielded the target molecules $\mathbf{4}$ and $\mathbf{5}$ in 35 and $28 \%$ isolated yields, respectively. Scheme 1 depicts the synthesis of the target molecules.

After synthesis and purification, the photophysical properties of the probes (2-5), including absorption and emission spectra in methanol, and extinction coefficients were determined (Figure 1, Table 1, and Figure S1 in the Supporting

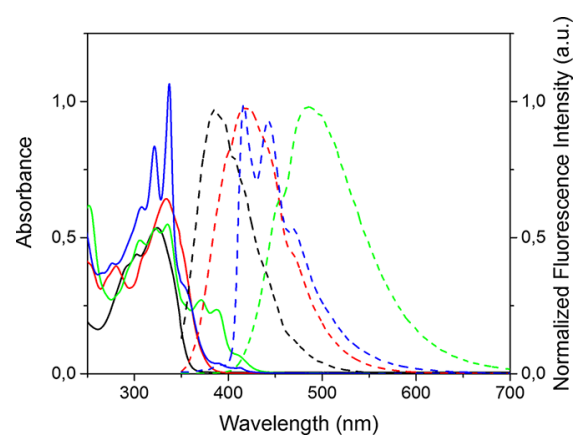

Figure 1. Absorption (solid lines) and normalized fluorescence (dashed lines) spectra of compounds $\mathbf{2 - 5}$ dissolved in methanol [20 $\mu \mathrm{M}]$ at $25^{\circ}$ C. 2 (black); 3 (red); 4 (green); and 5 (blue).

Table 1. Spectroscopic Properties of 2, 3, 4, and 5

$\begin{array}{ccccc}\text { probe } & \begin{array}{c}\lambda_{\max }(\mathrm{abs}) \\ {[\mathrm{nm}]}\end{array} & \varepsilon\left[\mathrm{L} \cdot \mathrm{M}^{-1} \mathrm{~cm}^{-1}\right]^{a} & \begin{array}{c}\lambda_{\text {max }}(\mathrm{em})^{b} \\ {[\mathrm{~nm}]}\end{array} & \begin{array}{c}\text { Stokes shift } \\ {[\mathrm{nm}]}\end{array} \\ \mathbf{2} & 325 & 25038 & 386 & 61 \\ \mathbf{3} & 334 & 30170 & 420 & 86 \\ \mathbf{4} & 335 & 27070 & 483 & 148 \\ \mathbf{5} & 337 & 47668 & 415 & 78\end{array}$

${ }^{a}$ Absorption spectra acquired at four different concentrations in methanol (2, 3, and 4 from 50 to $5 \mu \mathrm{M}$ and 5 from 10 to $2 \mu \mathrm{M}$ ). ${ }^{b}$ Excitation wavelength: $330 \mathrm{~nm}$, [probe] $=20 \mu \mathrm{M}$.

Information). Methanol was a good solvent for the probes where absorbance showed clear linearity over a concentration range up to $50 \mu \mathrm{M}$. In water, the absorbance for 2 also showed a clear linearity over a concentration range up to $50 \mu \mathrm{M}$ or more, 3 (up to $10 \mu \mathrm{M}$ ), 4 (up to $5 \mu \mathrm{M}$ ), and 5 (up to $2 \mu \mathrm{M}$ ) (Figure S1). Deviation from linearity above these concentrations shows that aggregation or micelle formation occurs above this concentration for each probe. As shown in Figure 1 and Table 1, the absorbance maxima are quite similar and centered around $330 \mathrm{~nm}$ for the whole series except for 4 that has a double-peak shoulder extending toward $400 \mathrm{~nm}$. The absorbance peak for 2 was at $325 \mathrm{~nm}, 3$ at $334 \mathrm{~nm}$, and $\mathbf{4}$ at 335 $\mathrm{nm}$. The lengthening of the $\pi$-conjugated system leads to a progressive red shift of the emission maximum from 386 to 483 nm. Compound $\mathbf{5}$ was an exception with the emission maximum at $415 \mathrm{~nm}$. The progressive shift is ascribed to the lengthening of the $\pi$-conjugation from the central moiety over the substituent, whereas the emission at $415 \mathrm{~nm}$ for the pyrene variant suggests a weak electronic interaction between the pyrene center and the dihydroxyphenyl substituent. ${ }^{37,52}$ In conclusion, these probes showed Stokes shifts ranging from 61 to $148 \mathrm{~nm}$ (Table 1) using methanol as the solvent.

ThT Fluorescence is $\mathrm{pH}$-Dependent. To benchmark our new probes with established amyloid probes, we used ThT. ThT fluorescence when bound to fibrils is known to be $\mathrm{pH}$ dependent. ${ }^{53}$ The fluorescence intensity of ThT when bound to different amyloid fibrils at acidic $\mathrm{pH}(\mathrm{pH}$ 3.0) or at neutral $\mathrm{pH}$ ( $\mathrm{pH} 7.5$ ) was compared. Herein, TTR, insulin, lysozyme, and A $\beta 1-42$ fibrils were measured. As shown in Figure 2A,B, the fluorescence of ThT bound to amyloid fibrils is very weak at $\mathrm{pH} 3.0$ probably because of the electrostatic repulsion of the dye by an increase in the positive charge. In general, the fluorescence intensity of ThT upon binding to fibrils increased greatly when comparing at acidic $\mathrm{pH}$ and neutral $\mathrm{pH}$ : TTR (4.3-fold), insulin (57.1-fold), and lysozyme (3.1-fold), in agreement with our previous paper. ${ }^{53}$

trans-Stilbenoids 4 and 5 Bind to Native and Fibrillar TTR. Previously, compounds $\mathbf{1}$ and $\mathbf{3}$ were reported to bind to native and misfolded fibrillar TTR, providing distinguishable emission spectra that shifted more than $100 \mathrm{~nm}$ for the two conformational states. ${ }^{36}$ Here, the binding response of the series $\mathbf{2}-\mathbf{5}$ to native TTR and TTR fibrils was also determined by using fluorescence spectroscopy (excitation: $330 \mathrm{~nm}$, emission: $350-600 \mathrm{~nm}$ ). Typical results are shown in Figure 3. Upon binding to native TTR, 4 generated two emission peaks at 449 and $476 \mathrm{~nm}$, with a total fluorescence intensity increase of about 6.1 times the intensity of the probe in buffer (Figure 3A). Upon binding to fibrillar TTR, there were also two emission peaks at 451 and $475 \mathrm{~nm}$; however, the dominating contribution was shifted toward the shorter wavelength (Figure 3A). Here, the apparent increase in fluorescence intensity was 8.8 -fold. As found from our results of $3,^{36}$ the spectrum of 4 bound to fibrils was blue-shifted compared with native TTR (Figure 3A). As shown in Figure $3 \mathrm{~B}$, probe 5, upon binding to either native or fibrillar TTR, showed very similar emission spectra with peaks at 420,445 , and $475 \mathrm{~nm}$. The difference here is the apparent fluorescence
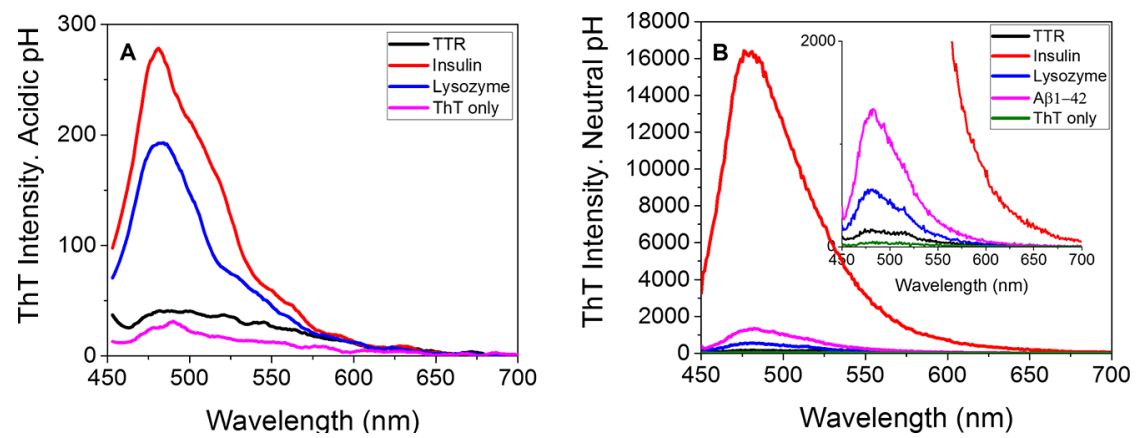

Figure 2. ThT shows pH-dependent fluorescence when bound to amyloid fibrils. (A) ThT fluorescence spectra of different amyloid fibrils in HOAc/ NaAc buffer ( $\mathrm{pH}$ 3.0). (B) ThT fluorescence spectra of different amyloid fibrils in PBS buffer ( $\mathrm{pH} 7.5$ ). All spectra were obtained at $5 \mu \mathrm{M}$ fibrils (on a monomer basis $)+1 \mu \mathrm{M}$ ThT with identical settings. 

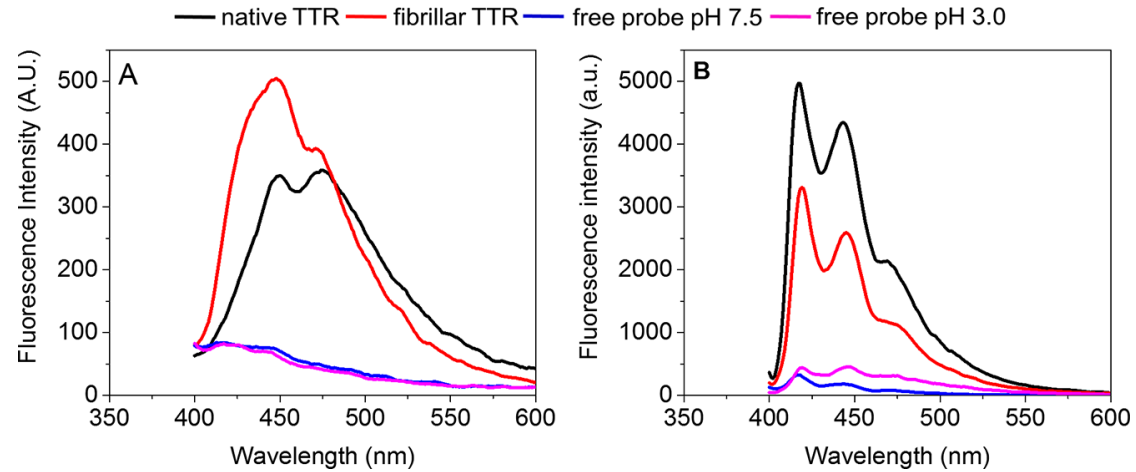

Figure 3. Fluorescence emission spectra of 4 and 5. (A) 4, upon binding to either native or fibrillar TTR and (B) 5 , upon binding to either native or fibrillar TTR. [native TTR] $=[$ TTR fibrils $]=5 \mu \mathrm{M}$ (on a monomer basis), [probe $]=1 \mu \mathrm{M}$, excitation wavelength: $330 \mathrm{~nm}$. Identical settings were used in all measurements.

Table 2. Spectroscopic and Binding Data of 2, 3, 4, and 5

\begin{tabular}{|c|c|c|c|c|c|c|c|c|c|}
\hline \multirow[b]{2}{*}{ probe } & \multirow[b]{2}{*}{$\lambda_{\mathrm{em} 1}{ }^{a}[\mathrm{~nm}]$} & \multicolumn{2}{|c|}{ TTR fibrils } & \multicolumn{2}{|c|}{ insulin fibrils } & \multicolumn{2}{|c|}{ lysozyme fibrils } & \multicolumn{2}{|c|}{ A $\beta 1-42$ fibrils } \\
\hline & & $\operatorname{Int}^{b}\left(\lambda_{\mathrm{em} 2}\right)$ & $K_{\mathrm{d}}^{c}[\mu \mathrm{M}]$ & $\operatorname{Int}^{b}\left(\lambda_{\mathrm{em} 2}\right)$ & $K_{\mathrm{d}}^{c}[\mu \mathrm{M}]$ & $\operatorname{Int}^{b}\left(\lambda_{\mathrm{em} 2}\right)$ & $K_{\mathrm{d}}{ }^{c}[\mu \mathrm{M}]$ & $\operatorname{Int}^{b}\left(\lambda_{\mathrm{em} 2}\right)$ & $K_{\mathrm{d}}^{c}[\mu \mathrm{M}]$ \\
\hline 2 & --- & $1.7(395)$ & $15.1 \pm 0.9$ & $7.5(382)$ & $8.0 \pm 1.6$ & $3.8(382)$ & $7.0 \pm 1.6$ & $2.6(384)$ & $4.3 \pm 0.2$ \\
\hline 3 & --- & $3.1(395)$ & $12.3 \pm 1.0$ & $13.7(410)$ & $4.5 \pm 0.4$ & $13.1(410)$ & $2.9 \pm 0.2$ & $6.9(408)$ & $2.2 \pm 0.4$ \\
\hline 4 & --- & $8.8(451)$ & $7.4 \pm 0.5$ & $91.4(451)$ & $3.7 \pm 0.6$ & $37.5(451)$ & $2.8 \pm 0.4$ & $10.3(451)$ & $1.6 \pm 0.1$ \\
\hline 5 & 420 & $6.3(420)$ & $6.0 \pm 0.3$ & $23.2(420)$ & $2.3 \pm 0.4$ & $8.9(420)$ & $1.6 \pm 0.3$ & $11.1(421)$ & $1.3 \pm 0.1$ \\
\hline
\end{tabular}

${ }^{a}$ The emission maxima of probes measured in HOAc/NaOAc buffer at $\mathrm{pH} 3.0$ or PBS buffer at $\mathrm{pH} 7.5 .{ }^{b}$ The fold increase in the fluorescence intensity upon binding to amyloid fibrils. The values in parentheses indicate the emission maxima of probes bound to amyloid fibrils measured in $\mathrm{NaOAc}$ buffer or PBS buffer (only for A $\beta 1-42$ fibrils). ${ }^{c}$ Dissociation constant: amyloid fibrils' titration on fixed concentration of probes ( $1 \mu \mathrm{M}$ for TTR fibrils, insulin fibrils, and lysozyme fibrils. $0.5 \mu \mathrm{M}$ for A $\beta 1-42$ fibrils). \pm denotes the standard deviation from $K_{\mathrm{d}}$ values obtained from two independent binding series. --- no apparent peak.
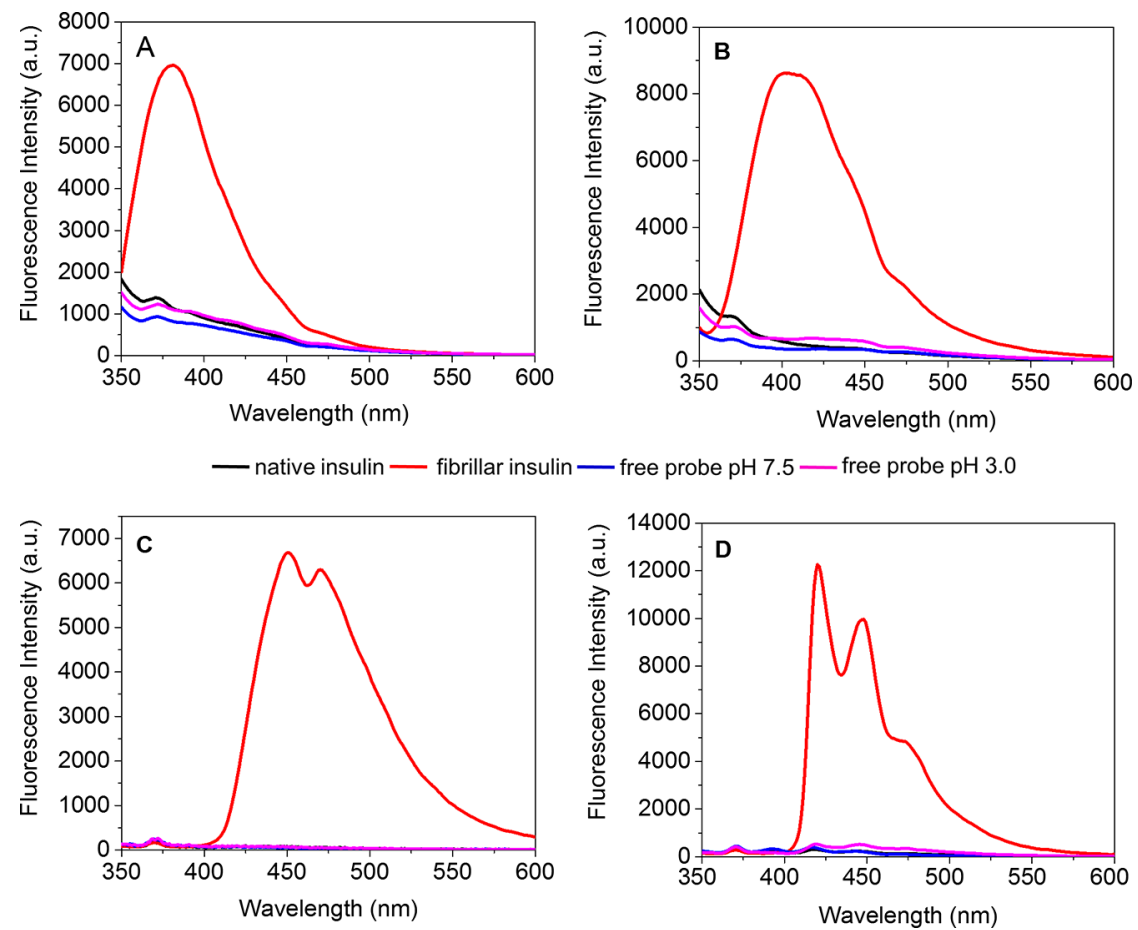

Figure 4. Fluorescence emission spectra of (A) 2, (B) 3, (C) 4, and (D) 5 bound to either native insulin or insulin fibrils. [native insulin] = [insulin fibrils] $=5 \mu \mathrm{M}$ (on a monomer basis), [probe] $=1 \mu \mathrm{M}$, excitation wavelength: $330 \mathrm{~nm}$. Identical settings were used in all measurements.

intensity increase: 15.8 -fold for native TTR compared with 6.3fold for fibrillar TTR (Figure 3B). These two conformational states of TTR are vastly different as shown by us using a large collection of biophysical techniques. ${ }^{36}$ We noted intense fluorescence of $\mathbf{5}$ bound to the native tetrameric TTR. The determined $K_{\mathrm{d}}$ value for $\mathbf{5}$ binding to the high-fluorescence site for native TTR was $0.2 \pm 0.01 \mu \mathrm{M}$ (Figure S2). The intensity increase of ThT bound to TTR fibrils was a mere 1.8, indicating that these new probes are more sensitive for the detection of TTR fibrils in vitro at acidic $\mathrm{pH}(\mathrm{pH} 3.0)$. 

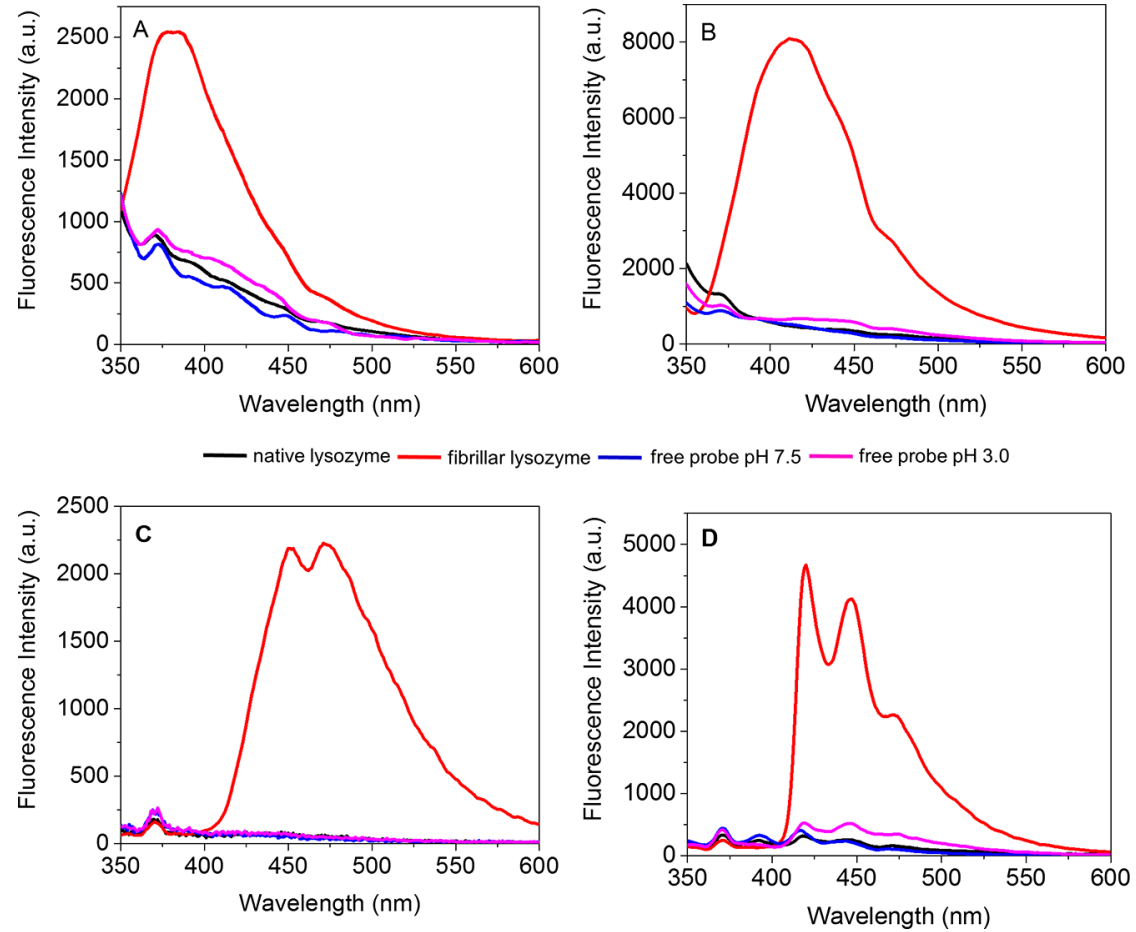

Figure 5. Fluorescence emission spectra of (A) 2, (B) 3, (C) 4, and (D) 5 bound to either native lysozyme or lysozyme fibrils. [native lysozyme] = [lysozyme fibrils] $=5 \mu \mathrm{M}$ (on a monomer basis), [probe] $=1 \mu \mathrm{M}$, excitation wavelength: $330 \mathrm{~nm}$. Identical settings were used in all measurements.

We further investigated the titration of TTR fibrils on a fixed concentration of probe $(1.0 \mu \mathrm{M})$ to determine the $K_{\mathrm{d}}$ values for the whole series. As found previously with 1 and 3 , two separate binding events were detected: $1\left(K_{\mathrm{d} 1}=0.11 \mu \mathrm{M}\right.$ and $\left.K_{\mathrm{d} 2}>10 \mu \mathrm{M}\right)$ and $3\left(K_{\mathrm{d} 1}=0.07 \mu \mathrm{M}\right.$ and $\left.K_{\mathrm{d} 2}>10 \mu \mathrm{M}\right){ }^{36}$ The high-affinity binding site showed minor fluorescence contribution; hence, we herein for fluorescence discrimination compare all probes for the high-fluorescence binding site. The $K_{\mathrm{d}}$ values were $15.1 \mu \mathrm{M}$ for $2,12.3 \mu \mathrm{M}$ for $3,7.4 \mu \mathrm{M}$ for 4 , and $6.0 \mu \mathrm{M}$ for $\mathbf{5}$, indicating that the affinity was in the following order: $5>$ $4>3>2$, for details see Table 2 and Figures S3-S6 in the Supporting Information.

We also experimentally addressed the finding of nearly identical spectra for compound $\mathbf{5}$ when bound to protofibrillar and native tetrameric TTR. Although the fluorescence intensity correlates well with the high intensity found in toluene, the spectral Stokes shift of probe $\mathbf{5}$ appears insensitive toward polarity of the binding site using four different solvents (PBS buffer, methanol, DMSO, and toluene) (Figure S7A). Notably, the relative intensities of three emission peaks do change, but the peak positions remain (Figure S7B). Our conclusion from the observation that the probe spectra bound to TTR are similar to that of $\mathbf{5}$ dissolved in toluene shows that both binding sites in the different conformational states are highly hydrophobic. Because the $K_{\mathrm{d}}$ toward native TTR is significantly lower than that of TTR protofibrils $(0.2 \mu \mathrm{M}$ compared with $6 \mu \mathrm{M})$, the occupancy of $\mathbf{5}$ on protofibrils is lower compared with native TTR under the conditions described in Figure 3, explaining the difference in intensity. This large $K_{d}$ difference underlines the difference of a highly ordered binding site in the tetramer ( $\mathrm{T} 4$ binding pocket) versus a more dynamic and fluid binding site on protofibrils. ${ }^{36}$

trans-Stilbenoids 2, 3, 4, and 5 Bind to Insulin Amyloid Fibrils. Similar experiments as discussed in the previous section were carried out to evaluate the probe series
(Chart 1) for detecting insulin fibrils and as a control to native monomeric/dimeric insulin at $\mathrm{pH}$ 3.0. As shown in Figure 4 and Table 2, when these probes were incubated with native insulin, we found no significant change in fluorescence, indicating that there were only weak interactions between the probes and native insulin. By contrast, upon binding to insulin fibrils, 2 showed an emission peak at $382 \mathrm{~nm}$ and an apparent fluorescence intensity increase (7.5-fold over free probe); 3 displayed an emission peak at $410 \mathrm{~nm}$ and an apparent fluorescence intensity increase (13.7-fold); 4 had an apparent emission peak at $451 \mathrm{~nm}$, a distinct fluorescence intensity increase (91.4-fold), and an additional peak at $471 \mathrm{~nm}$; and 5 had emission peaks at 420,445 , and $475 \mathrm{~nm}$ and an obvious fluorescence intensity increase (23.2-fold over free probe for the peak at $420 \mathrm{~nm}$ ). An apparent lower background fluorescence was observed from 2 to 5 , especially 4 and 5 very little fluorescence was given in either buffer, suggesting that these probes formed aggregates or micelles in the absence of fibrils. Compared with ThT at $\mathrm{pH} 3.0$, the intensity increase upon bound to insulin fibrils was in the following order: $4>5>$ $3>\mathrm{ThT}>2$, suggesting that 3, 4, and 5 are more sensitive probes to detect insulin fibrils in vitro at acidic $\mathrm{pH}(\mathrm{pH} 3.0)$.

To quantitatively evaluate the binding affinities of these probes to insulin fibrils, we measured the change in the fluorescence intensity by titrating a fixed low concentration of probes $(1.0 \mu \mathrm{M})$ with insulin fibrils. All probes mainly showed one distinct binding site with $K_{\mathrm{d}}=8.0 \mu \mathrm{M}$ for $2,4.5 \mu \mathrm{M}$ for 3, $3.7 \mu \mathrm{M}$ for 4 , and $2.3 \mu \mathrm{M}$ for $\mathbf{5}$ (for details see Table 2 and Figures S8-S11 in the Supporting Information). Groenning et $\mathrm{al}^{54}$ have reported that the $K_{\mathrm{d}}$ value of ThT binding to insulin fibrils was $10.4 \mu \mathrm{M}$ with one binding site. Therefore, the affinity of insulin fibrils to probes was in the following order: $5>4>3$ $>2>$ ThT. These results indicate that the probes can specifically bind to insulin amyloid fibrils with an obvious 

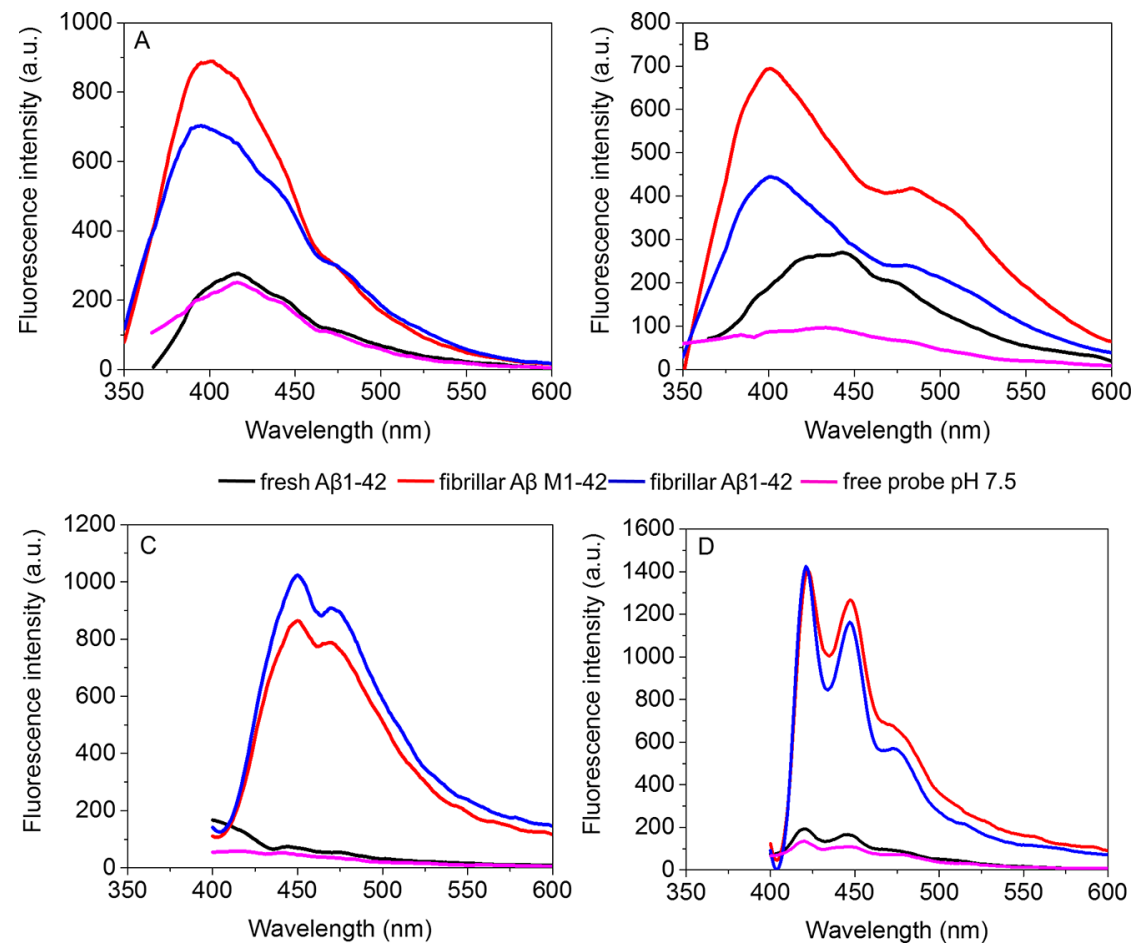

Figure 6. Fluorescence emission spectra of (A) 2, (B) 3, (C) 4, and (D) 5 bound to either freshly dissolved A $\beta 1-42$ or A $\beta 1-42$ fibrils as well as recombinant $\mathrm{A} \beta 1-42$ with an additional methionine in the $\mathrm{N}$-terminus $(\mathrm{A} \beta \mathrm{M} 1-42)$. Concentrations: [native $\mathrm{A} \beta 1-42]=[\mathrm{A} \beta 1-42$ fibrils] $=5 \mu \mathrm{M}$ (on a monomer basis), [probe] $=1 \mu \mathrm{M}$, excitation wavelength: $330 \mathrm{~nm}$. Identical settings were used in all measurements.

fluorescence intensity increase (from 7.5-fold to 91.4-fold) and moderate binding affinities.

trans-Stilbenoids 2, 3, 4, and 5 Bind to Lysozyme Amyloid Fibrils. The probe fluorescence response toward native lysozyme and lysozyme amyloid fibrils was assessed. As shown in Figure 5 and Table 2, there was essentially no fluorescence change of any probe with native lysozyme. On the contrary, upon binding to lysozyme fibrils, there is an increase in fluorescence intensity: 3.8-, 13.1-, 37.5-, and 8.9-fold for 2, 3, 4, and 5, respectively, as compared to the free probe. The emission spectra recorded for each probe upon binding to lysozyme fibrils were similar to those recorded upon binding to insulin fibrils, which means that the emission spectra for each probe occur from the same excited state. We also measured the $K_{\mathrm{d}}$ values: $7.0 \mu \mathrm{M}$ for $2,2.9 \mu \mathrm{M}$ for $3,2.8 \mu \mathrm{M}$ for 4 , and $1.6 \mu \mathrm{M}$ for 5 (for details see Table 2 and Figures S12-S15 in the Supporting Information). Sulatskaya et al. ${ }^{55}$ reported that ThT binds to lysozyme fibrils with two binding sites: $K_{\mathrm{d} 1}=0.13 \mu \mathrm{M}$ and $K_{\mathrm{d} 2}=17.86 \mu \mathrm{M}$, which suggested that the affinity of lysozyme fibrils to probes was in the order: $5>4 \approx 3>2>$ ThT $\left(K_{\mathrm{d} 2}=17.86 \mu \mathrm{M}\right)$. The fluorescence intensity was found to increase for probes 2,4 , and 5 but not to the same extent during binding to lysozyme fibrils as found for insulin fibrils. Probe 3 increased similarly (13.7-fold for insulin fibrils and 13.1-fold for lysozyme fibrils) for both fibril systems. Conclusively, these probes can specifically bind to lysozyme fibrils concomitant with the fluorescence intensity increase and overall with a higher affinity than that found for insulin fibrils.

trans-Stilbenoids 2, 3, 4, and 5 Bind to A $\beta 1-42$ Amyloid Fibrils. After specific detection of TTR, insulin, and lysozyme amyloid fibrils by these probes, we further extended the use of the series of probes in identifying $A \beta 1-42$ amyloid fibrils at neutral $\mathrm{pH}(\mathrm{pH} 7.5)$. As shown in Figure 6, 2 binds to $A \beta 1-42$ fibrils emitting fluorescence with a wavelength maximum at $384 \mathrm{~nm}$ and a 2.6-fold fluorescence intensity increase. 3 showed a 6.9-fold increased fluorescence intensity, at an emission maximum at $408 \mathrm{~nm} .4$ and 5 , both bind to $\mathrm{A} \beta 1$ 42 fibrils with an apparent 10.3- and 11.1-fold fluorescence intensity increase and emission maxima at around 450 and 421 $\mathrm{nm}$, respectively. Neither $\mathbf{2 , 4}$, or 5 fluoresced appreciably in the presence of freshly prepared native $\mathrm{A} \beta 1-42$, whereas 3 showed some binding to fresh $\mathrm{A} \beta 1-42$ (Figure 6B). The measured binding constant to $\mathrm{A} \beta 1-42$ fibrils is summarized in Table 2 and Figures S14-S17 in the Supporting Information. The affinity for A $\beta 1-42$ fibrils was stronger for $2\left(K_{d}=4.3 \mu \mathrm{M}\right), 3\left(K_{d}=2.2\right.$ $\mu \mathrm{M}), 4\left(K_{\mathrm{d}}=1.6 \mu \mathrm{M}\right)$, and $5\left(K_{\mathrm{d}}=1.3 \mu \mathrm{M}\right)$, compared with TTR, insulin, and lysozyme fibrils. The stronger binding affinities to $\mathrm{A} \beta 1-42$ fibrils (performed at $\mathrm{pH} 7.5$ ) compared with the other fibril types could indicate higher affinity at this $\mathrm{pH}$. Furthermore, it was found that the increase in the fluorescence intensity of 2,3 , and 4 bound to $A \beta 1-42$ fibrils was lower than that detected for insulin and lysozyme fibrils. Conclusively, all of the probes can specifically bind to A $\beta 1-42$ fibrils, followed by an increase in the fluorescence intensity (from 2.6-fold to 11.1-fold compared to the free probe) and with higher affinity compared with TTR, insulin, and lysozyme fibrils. For A $\beta 1-42$ fibrils, the ThT fluorescence increase (36.9fold) is even higher than that for $\mathbf{5}$ mainly because ThT is almost completely quenched in the free state. Various $K_{d}$ values for ThT have been reported toward $\mathrm{A} \beta$ fibrils in the $2-30 \mu \mathrm{M}$ range. $^{26,50}$

The majority of data in our study was collected on recombinant $A \beta 1-42$ with an extra methionine in the $\mathrm{N}$ terminus (A $\beta \mathrm{M} 1-42)$. The extra methionine has been reported not to influence kinetics or fibril morphology ${ }^{48}$ compared with the wild-type $\mathrm{A} \beta 1-42$. Importantly, two high-resolution structures were recently published where one used this construct $^{56}$ and the other study used a construct lacking the 

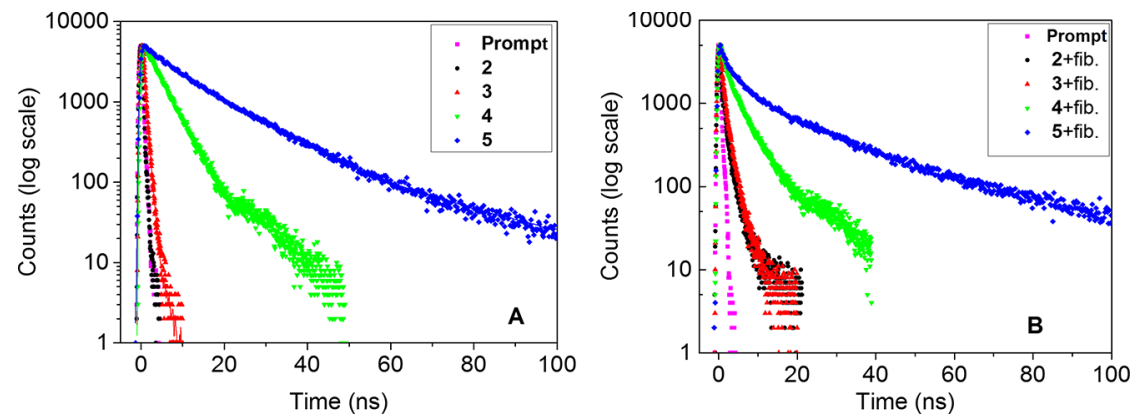

Figure 7. Fluorescence decays for excitation prompt (magenta), 2 (black), 3 (red), 4 (green), and 5 (blue) in degassed methanol (A) or bound to A $\beta 1-42$ fibrils (B).

Table 3. Fluorescence Lifetimes for the Probes in Degassed Methanol or Bound to A $\beta$ 1-42 Fibrils and Normalized PreExponential Factors

\begin{tabular}{|c|c|c|c|c|c|c|}
\hline probe & $a$ & $\lambda_{\mathrm{em} 1}^{b}[\mathrm{~nm}]$ & $\tau_{1}\left(\alpha_{1}\right)^{c}[\mathrm{~ns}]$ & $\tau_{2}\left(\alpha_{2}\right)^{c}[\mathrm{~ns}]$ & $\tau_{3}\left(\alpha_{3}\right)^{c}[\mathrm{~ns}]$ & $\tau_{\text {avg }}[\mathrm{ns}]$ \\
\hline \multirow[t]{2}{*}{2} & A & 395 & $<0.05(1)$ & & & $<0.05$ \\
\hline & B & 410 & $0.28(0.86)$ & $2.31(0.14)$ & & 1.33 \\
\hline \multirow[t]{2}{*}{3} & A & 415 & $0.52(1)$ & & & 0.52 \\
\hline & B & 420 & $0.23(0.54)$ & $1.65(0.46)$ & & 1.45 \\
\hline \multirow[t]{2}{*}{4} & A & 475 & $4.23(1)$ & & & 4.23 \\
\hline & B & 460 & $0.64(0.38)$ & $6.06(0.62)$ & & 5.73 \\
\hline \multirow[t]{2}{*}{5} & A & 425 & $11.00(0.77)$ & $29.30(0.23)$ & & 19.11 \\
\hline & B & 430 & $0.83(0.11)$ & $8.89(0.42)$ & $34.70(0.47)$ & 29.76 \\
\hline
\end{tabular}

${ }^{a}$ (A) Measured in degassed methanol, [probe] $=5 \mu \mathrm{M}$; (B) bound to $\mathrm{A} \beta 1-42$ fibrils in PBS buffer, [probe] $=5 \mu \mathrm{M}$ and $[\mathrm{A} \beta 1-42$ fibrils] $=20 \mu \mathrm{M}$. ${ }^{b}$ The emission maxima measured in PBS buffer upon binding to A $\beta 1-42$ fibrils. ${ }^{c}$ Lifetime $(\tau)$ and corresponding amplitude $(\alpha)$. The uncertainties of fluorescence lifetimes are within $10 \%$.

N-terminal methionine. ${ }^{57}$ Both fibril structures were found to be nearly identical. To verify this similar structure for our probe spectra, we prepared fibrils for both types. Nearly identical spectral profiles were observed (Figure 6).

Fluorescence Lifetimes of trans-Stilbenoids 2, 3, 4, and 5. The probes can specifically bind to four different amyloid fibrils, with a substantial fluorescence intensity increase and similar emission maxima for each fibril type. No appreciable binding was detected for native insulin, lysozyme, and A $\beta 1-42$. Only native TTR showed probe binding as expected from previous data, likely reflecting binding to the $\mathrm{T} 4$ binding site. ${ }^{36}$ Herein, we chose $A \beta 1-42$ fibrils as model fibrils to investigate the emission properties of the probes bound to amyloid fibrils from the viewpoint of the probe structures and the interaction modes between the probes and fibrils. We conducted time-resolved fluorescence measurements using the TCSPC method. The probes showed very weak and quenched fluorescence when dissolved without amyloid using the waterbased buffers applied for the amyloid or protein association experiments. A prerequisite for the assessment of fluorescence lifetimes is to have sufficient signal. Therefore, the intrinsic free lifetimes of the probes were determined using degassed methanol. In methanol, the solubility is high and by removing solvent oxygen, the parasitic quenching by oxygen, being important especially for probes with long lifetimes, was removed. Figure $7 \mathrm{~A}$ shows the decay curves of the probes dissolved in methanol, in which oxygen from air has been removed by flushing the sample with an argon gas. Thus, in degassed methanol solution, where emission strictly occurs from the free dyes, the fluorescence decay of the excited states of $\mathbf{2}$ is very fast $(<0.05 \mathrm{~ns})$. The fluorescence decay of $\mathbf{3}$ and $\mathbf{4}$ is single exponential with decay times of 0.52 and $4.23 \mathrm{~ns}$, respectively. The emission decay at $415 \mathrm{~nm}$ for 5 is double exponential in character with the $\tau_{\text {avg }}=19.11 \mathrm{~ns}\left(\tau_{1}=11.00 \mathrm{~ns}\right.$ and $\tau_{2}=29.30 \mathrm{~ns}$, with the corresponding pre-exponential factors $\alpha_{1}=0.77$ and $\alpha_{2}=0.23$, respectively) (Table 3). As expected for a pyrene fluorophore, probe $\mathbf{5}$ shows the longest lifetime. Consequently, the fluorescence lifetimes of the probes in degassed methanol are in the following order: $2<<3<4<$ 5 , indicating that the different aromatic rings (benzene, naphthyl, antracene, and pyrene) conjugated to the stilbene are promoting extended excited-state lifetimes.

To obtain sufficient signal to noise and to work under saturated conditions for the bound probe, the fluorescence decays for the probes bound to $\mathrm{A} \beta 1-42$ fibrils were investigated under the following conditions: [probe $]=5 \mu \mathrm{M},[\mathrm{A} \beta 1-42$ fibrils $]=20 \mu \mathrm{M}$ (on a monomer basis), and PBS buffer, $\mathrm{pH} 7.5$, at $25{ }^{\circ} \mathrm{C}$. By the law of mass action and the determined $K_{\mathrm{d}}$ values of the probes bound to $A \beta 1-42$ fibrils applied at a 10 -fold concentration above the $K_{\mathrm{d}}$ for 3,4 , and 5 , we expect $>90 \%$ of the signal to originate from the fibril-bound probe. Figure $7 \mathrm{~B}$ shows the decay curves of the probes bound to $A \beta 1-42$ fibrils. In general, there are small changes in the decay upon binding, but one can note a more pronounced contribution from longer decay time components, generating a "bent", multicomponent decay in all cases. Specifically, the fluorescence decay curves for 2, 3, and 4 are successfully analyzed using the doubleexponential kinetic law with good $\chi^{2}$ values, whereas a threecomponent decay is needed to accurately reproduce the decay of $\mathbf{5}$ with fibrils (see details in Table 3). Multiexponential decays can arise from populations of different binding sites in the aggregated protein, thus giving different lifetimes due to nearby quenching amino acid residues and/or solvent water. Multiexponential decays can also arise from mechanisms such as fluorescence resonance energy transfer, dynamic or static collision quenching, or combinations thereof, each model 

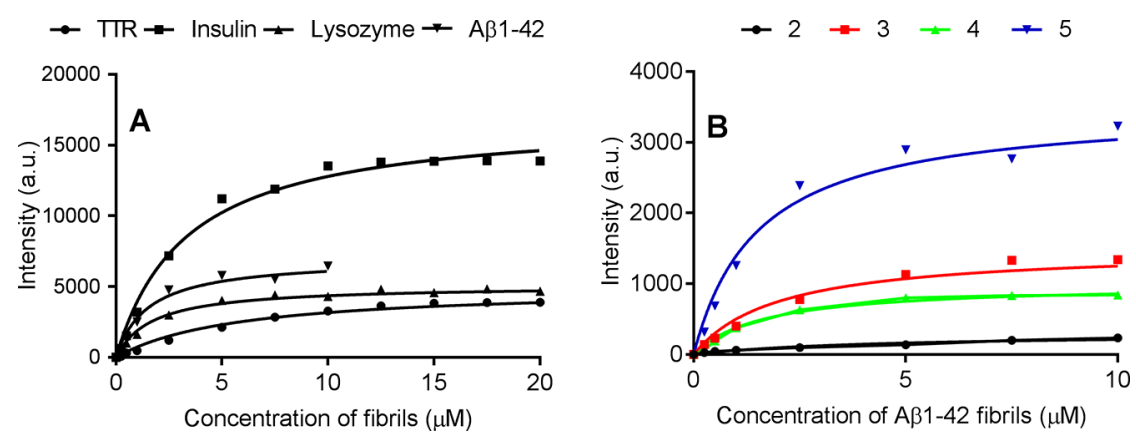

Figure 8. Representative saturation binding curves of amyloid fibrils to probes. (A) TTR, insulin, lysozyme, and A $\beta 1-42$ fibrils to 5. (B) A $\beta 1-42$ fibrils to $2,3,4$, and 5 .

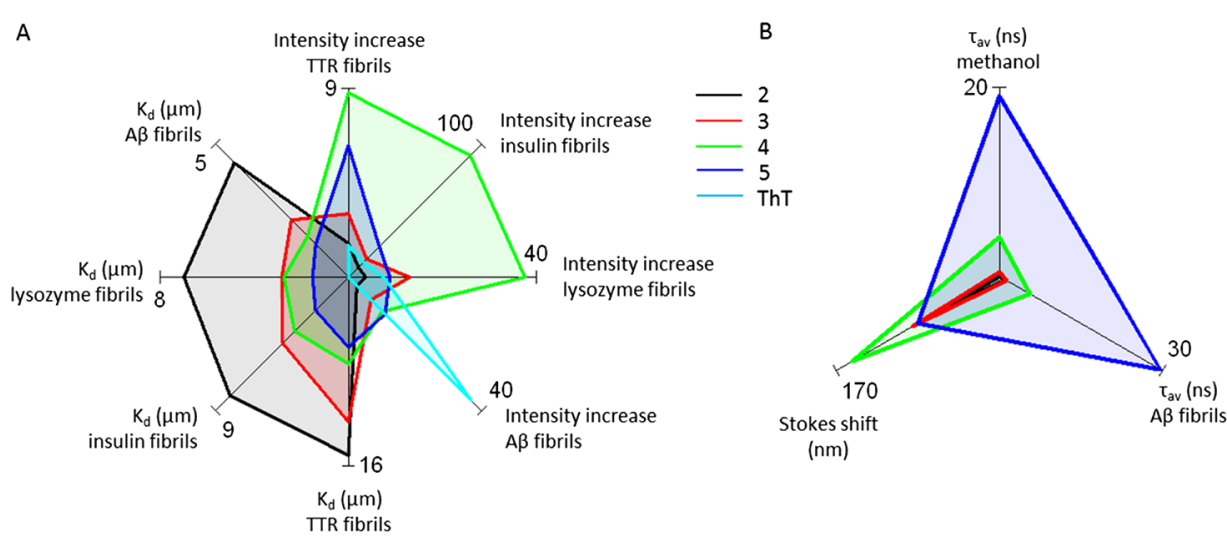

Figure 9. Starplot representation to compare all probe parameters in graphical format. (A) Binding properties represented by dissociation constants $\left(K_{\mathrm{d}}\right.$ in $\left.\mu \mathrm{M}\right)$ of the probes against different fibril types and the relative fold fluorescence intensity increase of the fibril-bound probe compared with the free probe. (B) Starplot representation of the photophysical properties, Stokes shift $(\mathrm{nm})$, and average fluorescence lifetime $\left(\tau_{\text {avg }}\right.$ in $\left.\mathrm{ns}\right)$ of the probes.

requiring a thorough analysis and definition of the averaging procedure. $^{58-60}$ To compare the different probes side-by-side, the multiexponential decays were summarized as intensity averaged lifetimes (see Experimental Section, Table 3). The average lifetime reflects the state population of each contributing lifetime, which we assume to best describe the binding sites on the amyloid fibril. The associated time constants are presented with the shortest first and the longest last (Table 3). As can be seen in Table 3, each probe, when bound to $\mathrm{A} \beta 1-42$ fibrils, showed a longer average lifetime than for the free probe in degassed methanol. For 2, 3, and 4, the existence of a long lifetime component $\left(\tau_{2}\right)$ population resulted from the probe incubated with $A \beta 1-42$ fibrils; the origin of a short phase $\left(\tau_{1}\right)$ can possibly be attributed to the small fraction of the free probe unbound to $\mathrm{A} \beta 1-42$ fibrils. Another possible origin of the short phase is the light-scattering effect from fibrils in PBS solution, although a spectral filter was used in the setup to minimize the effect of scatter from the excitation wavelength. For $\mathbf{5}$, the lifetime component $\tau_{3}$ most likely resulted from the probe bound to A $\beta 1-42$ fibrils. The pre-exponential factors (amplitude weights) of the multicomponent decays also show some systematic patterns. For 2, the pre-exponential factors of $\tau_{1}$ are found to be larger than that of $\tau_{2}$, indicating that the shorter decay of the free probe is predominant in the excited state. For 3, the pre-exponential factors of $\tau_{1}$ and $\tau_{2}$ are almost the same, meaning that the free probe and bound probe are nearly equal in the excited state. For 4, the pre-exponential factors of $\tau_{1}$ are smaller than that of $\tau_{2}$, demonstrating that the bound probe is predominant in the excited state. Conclusively, the binding of the series of new probes to $A \beta 1-42$ amyloid fibrils results in a fluorescent decay time that is substantially longer than the corresponding lifetime found in a good solvent (methanol).

\section{CONCLUSIONS}

Inspired by previous probe developments for TTR conformational states, ${ }^{36}$ we have herein successfully synthesized two new trans-stilbene-based fluorescent molecules $\mathbf{4}$ and $\mathbf{5}$ that can bind to both native and protofibrillar TTR. Both probes become highly fluorescent in the bound state. The amyloid-binding propensity for the series of four analogous trans-stilbenoids (two previously reported: 2 and 3, two new: 4 and 5) with different aromatic ring moieties was compared. Because of the common overall fold and core structure of amyloid fibrils, we expected these probes to bind to several amyloid fibrils while being refractive to native monomeric protein conformations. Importantly, all studied probes can bind specifically to amyloid fibrils of vastly heterologous proteins (insulin, lysozyme, TTR, and $\mathrm{A} \beta 1-42$ fibrils) with apparent fluorescence intensity augmentation and moderate affinities. The assays of fibrils were performed at the preferred $\mathrm{pH}$ for formation and stability, that is, $\mathrm{pH} 3.0$ for insulin, lysozyme, and TTR and at $\mathrm{pH} 7.5$ for $\mathrm{A} \beta 1-42$. To exemplify the binding response of the probes versus various amyloid fibrils, Figure $8 \mathrm{~A}$ shows the fluorescence response of $\mathbf{5}$ versus various amyloid fibril concentrations at a fixed concentration of probe. A corresponding probe comparison for $\mathbf{2 - 5}$ is shown for $\mathrm{A} \beta 1-42$ fibrils (Figure $8 \mathrm{~B}$ ). 
Both datasets display the various fluorescence responses being both protein- and probe-dependent.

The fluorescence lifetime of ThT is rather short: $80 \%$ is $<1$ ns and 20\% 3.9 ns. $^{29}$ One specific aim of the current study was to develop long lifetime fluorescent probes to allow measurements of solution dynamics of amyloid species. To our knowledge, no small-molecule amyloid targeting probes have been reported with pyrene or anthracene directly binding to the amyloid fibril binding sites. In previous work, we have shown the virtue of pyrene-based cysteine-specific probes covalently linked to TTR for size determination of TTR oligomers up to 20 mers, $^{61}$ and we hypothesized on the applicability of extended lifetime noncovalent amyloid targeting probes described herein. ${ }^{17}$ The fluorescence lifetimes of the amyloid probes described in this work in degassed methanol are ranked as $(2<0.05 \mathrm{~ns})<3=0.52 \mathrm{~ns}<\mathbf{4}=4.23 \mathrm{~ns}<\mathbf{5}=19.11 \mathrm{~ns}$, indicating that the different aromatic ring moieties determine the respective probe residence time in the excited state. When bound to $\mathrm{A} \beta 1-42$ fibrils, the lifetimes are $1.3 \mathrm{~ns}(2), 1.5 \mathrm{~ns}$ (3), $5.7 \mathrm{~ns}(4)$, and $29.8 \mathrm{~ns}(5)$. Hence, each probe bound to $A \beta 1$ 42 fibrils showed longer lifetime than in degassed methanol, suggesting that the probe binding sites are hydrophobic and well-shielded from the surrounding water solvent. Obviously, the pyrene-based $\mathbf{5}$ showed the longest fluorescence lifetime when bound to $A \beta 1-42$ fibrils, opening the opportunity for size determination of the oligomerization process by dynamic fluorescence spectroscopy. To make a palpable overall comparison of the probes against various amyloid fibrils, we generated a starplot (Figure 9A) to compare various $K_{d}$ values and fluorescence increase for the respective probe. This graphical representation illustrates that 4 shows the strongest fluorescence increase for fibrils at acidic $\mathrm{pH}$ and that the affinity (low $K_{d}$ ) generally increases as the hydrophobicity of the probe increases, with the strongest binding for 5. Furthermore, a starplot representation of the photophysical properties, Stokes shift, and fluorescence lifetimes clearly display a similar separation with highest Stokes shift for $\mathbf{4}$ and the longest fluorescence lifetimes for $\mathbf{5}$ (Figure 9B). We foresee that this class of probes will be useful for amyloid fibril research.

\section{ASSOCIATED CONTENT}

\section{S Supporting Information}

The Supporting Information is available free of charge on the ACS Publications website at DOI: 10.1021/acsomega.7b00535.

Synthesis of compounds 4 and 5; absorbance spectra of all compounds; emission spectra in various solvents for compound $\mathbf{5}$ and binding of $\mathbf{5}$ toward native TTR; and saturation binding curves of all compounds to different fibrils: TTR, insulin, lysozyme, and A $\beta 1-42$ fibrils (PDF)

\section{AUTHOR INFORMATION}

\section{Corresponding Author}

*E-mail: per.hammarstrom@liu.se, perha@ifm.liu.se. Phone: +4613285690 (P.H.).

\section{ORCID 1}

Per Hammarström: 0000-0001-5827-3587

\section{Notes}

The authors declare no competing financial interest.

\section{ACKNOWLEDGMENTS}

We thank Maria Thörnkvist for assistance with preparation of TTR. This work was supported by the Swedish Research Council, the Swedish Alzheimer Foundation, the Swedish Brain Foundation, LiU-Neuro, and Göran Gustafsson Foundation. M.L. is grateful to Linköping University for a guest professor tenure during which a part of this work was carried out.

\section{REFERENCES}

(1) Chiti, F.; Dobson, C. M. Protein Misfolding, Functional Amyloid, and Human Disease. Annu. Rev. Biochem. 2006, 75, 333-366.

(2) Ross, C. A.; Poirier, M. A. Protein Aggregation and Neurodegenerative Disease. Nat. Med. 2004, 10, S10-S17.

(3) Dobson, C. M. Protein Folding and Misfolding. Nature 2003, 426, 884-890.

(4) Ban, T.; Hamada, D.; Hasegawa, K.; Naiki, H.; Goto, Y. Direct Observation of Amyloid Fibril Growth Monitored by Thioflavin T Fluorescence. J. Biol. Chem. 2003, 278, 16462-16465.

(5) Harper, J. D.; Lansbury, P. T. Models of Amyloid Seeding in Alzheimier's Disease and Scrapie: Mechanistic Truths and Physiological Consequences of the Time-Dependent Solubility of Amyloid Proteins. Annu. Rev. Biochem. 1997, 66, 385-407.

(6) Bulic, B.; Pickhardt, M.; Schmidt, B.; Mandelkow, E.-M.; Waldmann, H.; Mandelkow, E. Development of Tau Aggregation Inhibitors for Alzheimer's Disease. Angew. Chem., Int. Ed. 2009, 48, $1740-1752$.

(7) Selkoe, D. J. Folding Proteins in Fatal Ways. Nature 2003, 426, 900-904.

(8) Sipe, J. D. Amyloidosis. Annu. Rev. Biochem. 1992, 61, 947-975.

(9) Eva, Ž. Amyloid-Fibril Formation. Eur. J. Biochem. 2002, 269, 3362-3371.

(10) Pepys, M. B. Pathogenesis, Diagnosis and Treatment of Systemic Amyloidosis. Philos. Trans. R. Soc., B 2001, 356, 203-211.

(11) Sunde, M.; Serpell, L. C.; Bartlam, M.; Fraser, P. E.; Pepys, M. B.; Blake, C. C. F. Common Core Structure of Amyloid Fibrils by Synchrotron X-Ray Diffraction. J. Mol. Biol. 1997, 273, 729-739.

(12) Makin, O. S.; Serpell, L. C. Structures for Amyloid Fibrils. FEBS J. 2005, 272, 5950-5961.

(13) Serpell, L. C.; Sunde, M.; Benson, M. D.; Tennent, G. A.; Pepys, M. B.; Fraser, P. E. The Protofilament Substructure of Amyloid Fibrils. J. Mol. Biol. 2000, 300, 1033-1039.

(14) Krebs, M. R. H.; Bromley, E. H. C.; Donald, A. M. The Binding of Thioflavin-T to Amyloid Fibrils: Localisation and Implications. J. Struct. Biol. 2005, 149, 30-37.

(15) Hwang, W.; Zhang, S.; Kamm, R. D.; Karplus, M. Kinetic Control of Dimer Structure Formation in Amyloid Fibrillogenesis. Proc. Natl. Acad. Sci. U.S.A. 2004, 101, 12916-12921.

(16) Pedersen, J. S.; Dikov, D.; Flink, J. L.; Hjuler, H. A.; Christiansen, G.; Otzen, D. E. The Changing Face of Glucagon Fibrillation: Structural Polymorphism and Conformational Imprinting. J. Mol. Biol. 2006, 355, 501-523.

(17) Lindgren, M.; Hammarström, P. Amyloid Oligomers: Spectroscopic Characterization of Amyloidogenic Protein States. FEBS J. 2010, 277, 1380-1388.

(18) Nilsson, M. R. Techniques to Study Amyloid Fibril Formation in Vitro. Methods 2004, 34, 151-160.

(19) Nilsson, K. P. R.; Hammarström, P. Luminescent Conjugated Polymers: Illuminating the Dark Matters of Biology and Pathology. Adv. Mater. 2008, 20, 2639-2645.

(20) LeVine, H., III; Peter, K.; Nilsson, R.; Hammarström, P. Reporters of Amyloid Structural Polymorphism. In Bio-Nanoimaging: Protein Misfolding and Aggregation; Elsevier: London, 2014; Chapter 7.

(21) Ban, T.; Hamada, D.; Hasegawa, K.; Naiki, H.; Goto, Y. Direct Observation of Amyloid Fibril Growth Monitored by Thioflavin T Fluorescence. J. Biol. Chem. 2003, 278, 16462-16465.

(22) McParland, V. J.; Kad, N. M.; Kalverda, A. P.; Brown, A.; Kirwin-Jones, P.; Hunter, M. G.; Sunde, M.; Radford, S. E. Partially 
Unfolded States of $\beta 2$-Microglobulin and Amyloid Formation in Vitro. Biochemistry 2000, 39, 8735-8746.

(23) Kim, Y.-S.; Randolph, T. W.; Manning, M. C.; Stevens, F. J.; Carpenter, J. F. Congo Red Populates Partially Unfolded States of an Amyloidogenic Protein to Enhance Aggregation and Amyloid Fibril Formation. J. Biol. Chem. 2003, 278, 10842-10850.

(24) Khurana, R.; Uversky, V. N.; Nielsen, L.; Fink, A. L. Is Congo Red an Amyloid-Specific Dye? J. Biol. Chem. 2001, 276, 22715-22721.

(25) LeVine, H., III [18] Quantification of $\beta$-Sheet Amyloid Fibril Structures with Thioflavin T. Methods Enzymol. 1999, 309, 274-284.

(26) Levine, H. Thioflavine T Interaction with Synthetic Alzheimer's Disease $\beta$-Amyloid Peptides: Detection of Amyloid Aggregation in Solution. Protein Sci. 2008, 2, 404-410.

(27) Maskevich, A. A.; Stsiapura, V. I.; Kuzmitsky, V. A.; Kuznetsova, I. M.; Povarova, O. I.; Uversky, V. N.; Turoverov, K. K. Spectral Properties of Thioflavin $\mathrm{T}$ in Solvents with Different Dielectric Properties and in a Fibril-Incorporated Form. J. Proteome Res. 2007, 6, 1392-1401.

(28) Stsiapura, V. I.; Maskevich, A. A.; Kuzmitsky, V. A.; Uversky, V. N.; Kuznetsova, I. M.; Turoverov, K. K. Thioflavin T as a Molecular Rotor: Fluorescent Properties of Thioflavin $\mathrm{T}$ in Solvents with Different Viscosity. J. Phys. Chem. B 2008, 112, 15893-15902.

(29) Lindgren, M.; Sörgjerd, K.; Hammarström, P. Detection and Characterization of Aggregates, Prefibrillar Amyloidogenic Oligomers, and Protofibrils Using Fluorescence Spectroscopy. Biophys. J. 2005, 88, 4200-4212.

(30) Arja, K.; Sjölander, D.; Åslund, A.; Prokop, S.; Heppner, F. L.; Konradsson, P.; Lindgren, M.; Hammarström, P.; Åslund, K. O. A.; Nilsson, K. P. R. Enhanced Fluorescent Assignment of Protein Aggregates by an Oligothiophene-Porphyrin-Based Amyloid Ligand. Macromol. Rapid Commun. 2013, 34, 723-730.

(31) Berezin, M. Y.; Achilefu, S. Fluorescence Lifetime Measurements and Biological Imaging. Chem. Rev. 2010, 110, 2641-2684.

(32) Klabunde, T.; Petrassi, H. M.; Oza, V. B.; Raman, P.; Kelly, J. W.; Sacchettini, J. C. Rational Design of Potent Human Transthyretin Amyloid Disease Inhibitors. Nat. Struct. Mol. Biol. 2000, 7, 312-321.

(33) Hammarström, P.; Jiang, X.; Hurshman, A. R.; Powers, E. T.; Kelly, J. W. Sequence-Dependent Denaturation Energetics: A Major Determinant in Amyloid Disease Diversity. Proc. Natl. Acad. Sci. U.S.A. 2002, 99, 16427-16432.

(34) Dorbala, S.; Vangala, D.; Semer, J.; Strader, C.; Bruyere, J. R., Jr.; Di Carli, M. F.; Moore, S. C.; Falk, R. H. Imaging Cardiac Amyloidosis: A Pilot Study Using ${ }^{18}$ F-Florbetapir Positron Emission Tomography. Eur. J. Nucl. Med. Mol. Imaging 2014, 41, 1652-1662.

(35) Furukawa, K.; Ikeda, S.-i.; Okamura, N.; Tashiro, M.; Tomita, N.; Furumoto, S.; Iwata, R.; Yanai, K.; Kudo, Y.; Arai, H. Cardiac Positron-Emission Tomography Images with an Amyloid-Specific Tracer in Familial Transthyretin-Related Systemic Amyloidosis. Circulation 2012, 125, 556-557.

(36) Campos, R. I.; Wu, X.; Elgland, M.; Konradsson, P.; Hammarström, P. Novel Trans-Stilbene-Based Fluorophores as Probes for Spectral Discrimination of Native and Protofibrillar Transthyretin. ACS Chem. Neurosci. 2016, 7, 924-940.

(37) Wanninger-Weiß, C.; Wagenknecht, H.-A. Synthesis of 5-(2Pyrenyl)-2'-Deoxyuridine as a DNA Modification for ElectronTransfer Studies: The Critical Role of the Position of the Chromophore Attachment. Eur. J. Org. Chem. 2008, 64-71.

(38) Coventry, D. N.; Batsanov, A. S.; Goeta, A. E.; Howard, J. A. K.; Marder, T. B.; Perutz, R. N. Selective Ir-Catalysed Borylation of Polycyclic Aromatic Hydrocarbons: Structures of Naphthalene-2,6Bis(Boronate), Pyrene-2,7-Bis(Boronate) and Perylene-2,5,8,11-Tetra(Boronate) Esters. Chem. Commun. 2005, 2172-2174.

(39) Crawford, A. G.; Liu, Z.; Mkhalid, I. A. I.; Thibault, M.-H.; Schwarz, N.; Alcaraz, G.; Steffen, A.; Collings, J. C.; Batsanov, A. S.; Howard, J. A. K.; Marder, T. B. Synthesis of 2- and 2,7-Functionalized Pyrene Derivatives: An Application of Selective $\mathrm{C}-\mathrm{H}$ Borylation. Chem.-Eur. J. 2012, 18, 5022-5035.

(40) Yamato, T.; Noda, K.; Tsuzuki, H. Medium-Sized Cyclophanes. Part 56. 8-Substituted 5-Tert-Butyl[2.2]Metaparacyclophane-1,9-Di- enes. Preparation, X-Ray Diffraction Study and Their Treatment with Lewis and Protic Acids. New J. Chem. 2001, 25, 721-727.

(41) Harvey, R. G.; Schmolka, S.; Cortez, C.; Lee, H. Syntheses of 2Bromopyrene and 2-Hydroxypyrene. Synth. Commun. 1988, 18, 22072209.

(42) Albert, S.; Horbach, R.; Deising, H. B.; Siewert, B.; Csuk, R. Synthesis and Antimicrobial Activity of (E) Stilbene Derivatives. Bioorg. Med. Chem. 2011, 19, 5155-5166.

(43) Fisher, A. J.; Kerrigan, F. A New Convenient Synthesis of 1-(3Hydroxy-4-Methoxyphenyl)Ethane-1,2-Diol (Iso-Mhpg) and Its Enantiomers. Synth. Commun. 1998, 28, 2959-2968.

(44) Groenning, M.; Campos, R. I.; Fagerberg, C.; Rasmussen, A. A.; Eriksen, U. H.; Powers, E. T.; Hammarström, P. Thermodynamic Stability and Denaturation Kinetics of a Benign Natural Transthyretin Mutant Identified in a Danish Kindred. Amyloid 2011, 18, 35-46.

(45) Raz, A.; Goodman, D. S. The Interaction of Thyroxine with Human Plasma Prealbumin and with the Prealbumin-Retinol-Binding Protein Complex. J. Biol. Chem. 1969, 244, 3230-3237.

(46) Krebs, M. R. H.; Morozova-Roche, L. A.; Daniel, K.; Robinson, C. V.; Dobson, C. M. Observation of Sequence Specificity in the Seeding of Protein Amyloid Fibrils. Protein Sci. 2004, 13, 1933-1938.

(47) Mishra, R.; Sörgjerd, K.; Nyström, S.; Nordigården, A.; Yu, Y.C.; Hammarström, P. Lysozyme Amyloidogenesis Is Accelerated by Specific Nicking and Fragmentation but Decelerated by Intact Protein Binding and Conversion. J. Mol. Biol. 2007, 366, 1029-1044.

(48) Walsh, D. M.; Thulin, E.; Minogue, A. M.; Gustavsson, N.; Pang, E.; Teplow, D. B.; Linse, S. A Facile Method for Expression and Purification of the Alzheimer's Disease-Associated Amyloid $\beta$-Peptide. FEBS J. 2009, 276, 1266-1281.

(49) Thordarson, P. Determining Association Constants from Titration Experiments in Supramolecular Chemistry. Chem. Soc. Rev. 2011, 40, 1305-1323.

(50) Lockhart, A.; Ye, L.; Judd, D. B.; Merritt, A. T.; Lowe, P. N.; Morgenstern, J. L.; Hong, G.; Gee, A. D.; Brown, J. Evidence for the Presence of Three Distinct Binding Sites for the Thioflavin T Class of Alzheimer's Disease Pet Imaging Agents on $\beta$-Amyloid Peptide Fibrils. J. Biol. Chem. 2005, 280, 7677-7684.

(51) Schütz, A. K.; Soragni, A.; Hornemann, S.; Aguzzi, A.; Ernst, M.; Böckmann, A.; Meier, B. H. The Amyloid-Congo Red Interface at Atomic Resolution. Angew. Chem., Int. Ed. 2011, 50, 5956-5960.

(52) Crawford, A. G.; Dwyer, A. D.; Liu, Z.; Steffen, A.; Beeby, A.; Pålsson, L.-O.; Tozer, D. J.; Marder, T. B. Experimental and Theoretical Studies of the Photophysical Properties of 2- and 2,7Functionalized Pyrene Derivatives. J. Am. Chem. Soc. 2011, 133, 13349-13362.

(53) Mishra, R.; Sjölander, D.; Hammarström, P. Spectroscopic Characterization of Diverse Amyloid Fibrilsin Vitro by the Fluorescent Dye Nile Red. Mol. BioSyst. 2011, 7, 1232-1240.

(54) Groenning, M.; Norrman, M.; Flink, J. M.; van de Weert, M.; Bukrinsky, J. T.; Schluckebier, G.; Frokjaer, S. Binding Mode of Thioflavin T in Insulin Amyloid Fibrils. J. Struct. Biol. 2007, 159, 483497.

(55) Sulatskaya, A. I.; Kuznetsova, I. M.; Turoverov, K. K. Interaction of Thioflavin T with Amyloid Fibrils: Fluorescence Quantum Yield of Bound Dye. J. Phys. Chem. B 2012, 116, 2538-2544.

(56) Colvin, M. T.; Silvers, R.; Ni, Q. Z.; Can, T. V.; Sergeyev, I.; Rosay, M.; Donovan, K. J.; Michael, B.; Wall, J.; Linse, S.; Griffin, R. G. Atomic Resolution Structure of Monomorphic A $\beta 42$ Amyloid Fibrils. J. Am. Chem. Soc. 2016, 138, 9663-9674.

(57) Wälti, M. A.; Ravotti, F.; Arai, H.; Glabe, C. G.; Wall, J. S.; Böckmann, A.; Güntert, P.; Meier, B. H.; Riek, R. Atomic-resolution structure of a disease-relevant $\mathrm{A} \beta(1-42)$ amyloid fibril. Proc. Natl. Acad. Sci. U.S.A. 2016, 113, E4976-E4984.

(58) Webber, S. E. The Role of Time-Dependent Measurements in Elucidating Static Versus Dynamic Quenching Processes. Photochem. Photobiol. 1997, 65, 33-38.

(59) Sillen, A.; Engelborghs, Y. The Correct Use of "Average" Fluorescence Parameters. Photochem. Photobiol. 1998, 67, 475-486. 
(60) Lakowicz, J. R. Principles of Fluorescence Spectroscopy; Springer: New York, 2010.

(61) Sörgjerd, K.; Klingstedt, T.; Lindgren, M.; Kågedal, K.; Hammarström, P. Prefibrillar Transthyretin Oligomers and Cold Stored Native Tetrameric Transthyretin Are Cytotoxic in Cell Culture. Biochem. Biophys. Res. Commun. 2008, 377, 1072-1078. 